\title{
A Rare Case of Cervical Dumbbell Meningioma with the C2 Spinous Process Preservation
}

\author{
Tatsuya Sato1, Takatoshi Okuda', Tsuyoshi Saito², Ikuho Yonezawa1, Shingo Onda1, \\ Yukitoshi Shimamura1, Kei Yoshikawa1, Hiromitsu Takano', Kazuo Kaneko' ${ }^{1}$ \\ ${ }^{1}$ Department of Orthopedic Surgery, Juntendo University School of Medicine 2-1-1 Hongo, Tokyo, Japan \\ ${ }^{2}$ Department of Human Pathology, Juntendo University School of Medicine 2-1-1 Hongo, Tokyo, Japan \\ Email: t-sato@juntendo.ac.jp
}

Received 18 March 2016; accepted 18 April 2016; published 21 April 2016

Copyright (C) 2016 by authors and Scientific Research Publishing Inc.

This work is licensed under the Creative Commons Attribution International License (CC BY). http://creativecommons.org/licenses/by/4.0/

(c) (i) Open Access

\begin{abstract}
Dumbbell growth is often observed in schwannoma but rarely in meningioma. In particular, the occurrence of dumbbell meningioma at the cervical cord level in Japan is markedly rare. We reported an elderly case with symptomatic meningioma that developed in a dumbbell shape from cervical spine and was treated successfully by surgery.
\end{abstract}

Keywords

Dumbbell Meningioma, Spinous Process Preservation, Cervical Spine, Spinal Tumor, Spinal Surgery

\section{Introduction}

Intradural extramedullary tumors account for approximately $70 \%-75 \%$ of spinal cord tumors, and meningioma and schwannoma account for approximately $70 \%$ of them [1] [2]. In Western countries, the occurrence of meningioma and schwannoma is comparable [2], whereas the occurrence of meningioma in Japan is approximately one-fourth of that of schwannoma [3]. Dumbbell growth is often observed in schwannoma, but rarely in meningioma. In particular, the occurrence of a dumbbell meningioma at the cervical cord level is markedly rare. Here, we reported an elderly case with symptomatic meningioma that developed and grew in a dumbbell shape at the spinal cord and was treated successfully by surgery.

\section{Case Report}

A 76-year-old female had complained of numbness in her right hand for 10 months and visited a nearby clinic

How to cite this paper: Sato, T., Okuda, T., Saito, T., Yonezawa, I., Onda, S., Shimamura, Y., Yoshikawa, K., Takano, H. and Kaneko, K. (2016) A Rare Case of Cervical Dumbbell Meningioma with the C2 Spinous Process Preservation. Open Journal of Orthopedics, 6, 98-102. http://dx.doi.org/10.4236/ojo.2016.64014 
for rehabilitation. She was referred to our hospital for pain and weakness in the left upper and lower extremities, impaired coordinated movement of the left hand, and pain in the right lower extremity. Physical examinations revealed decreased muscle strength of the left upper and lower extremities, pain in the upper and lower extremities, palsy at the $\mathrm{C} 5$ region of the left upper extremity, coordination disturbance, bilateral hyper reflex of the biceps and its distal tendons, and spastic gait with a Japanese Orthopedic Association (JOA) score of 11 points.

Magnetic resonance imaging (MRI) demonstrated a well-demarcated mass, $2 \mathrm{~cm}$ in size that exhibited slightly higher intensity on T2-weighted imaging, iso-intensity on T1-weighted imaging, and homogenous contrast enhancement with the dural tail sign on contrast imaging, which compressed the cervical cord. The mass, surrounding the vertebral artery, extended to the outer space of the left $\mathrm{C} 3 / 4$ intervertebral foramen and was categorized as a type-2 dumbbell tumor according to Eden's classification (Figure 1).

The patient underwent operation to excise the tumor. The $\mathrm{C} 2$ spinous process was half-dissected and inverted to the left with the rectus capitis posterior major muscle, oblique capitis inferior muscle, and semispinalis cervicis muscle still attached. Subsequently, the medial half of the facet joint on the left side of the vertebral arch was partially resected and a C3-4 half-opened vertebral arch was created. Then, the whole view of the extraforaminal part of the tumor, extending from the $\mathrm{C} 2$ tail to $\mathrm{C} 4$, was exposed (Figure 2).

First, the intratumoral pressure of the extradural section of the tumor was reduced. With regard to the anterior section of the tumor involving the vertebral artery, tumor enucleation was carried out as much as possible. At
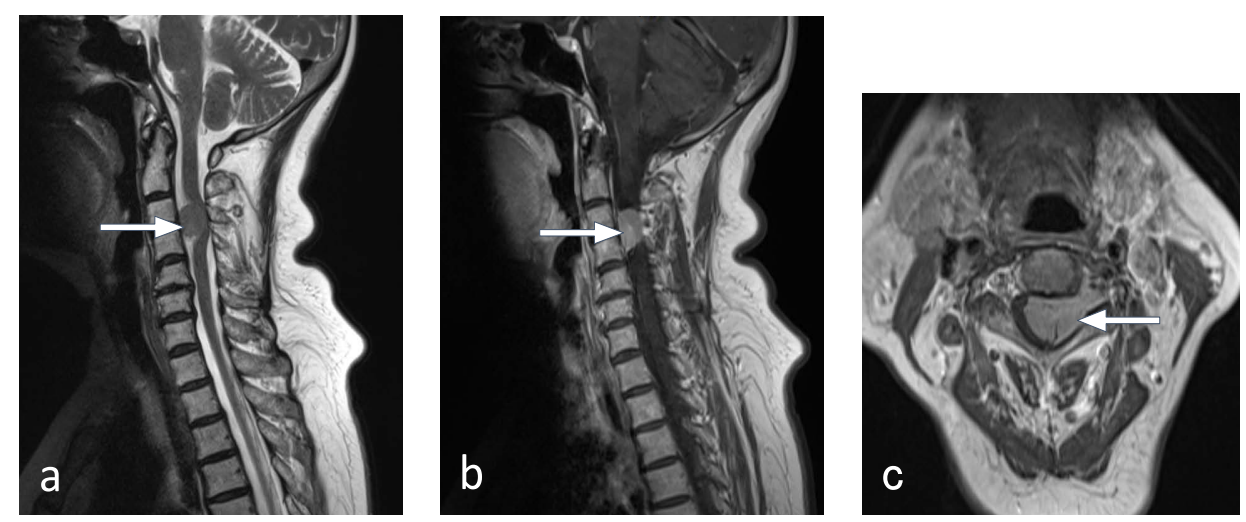

Figure 1. Preoperative MRI. (a) A mass with slightly high intensity signals was observed at the C3/4 level by sagittal MRI on T2-weighted imaging (arrow); (b) Sagittal; and (c) Axial Gadolinium-enhanced T1-weighted images. A well-demarcated dumbbell mass, $2 \mathrm{~cm}$ in size, and homogeneously enhanced with the dural tail sign, compressed the cervical spinal cord at the $\mathrm{C} 3 / 4$ level. The mass, extending from the intradural space to the left $\mathrm{C} 3 / 4$ neural foramen in a dumbbell shape, was also present around the left vertebral artery (arrow).
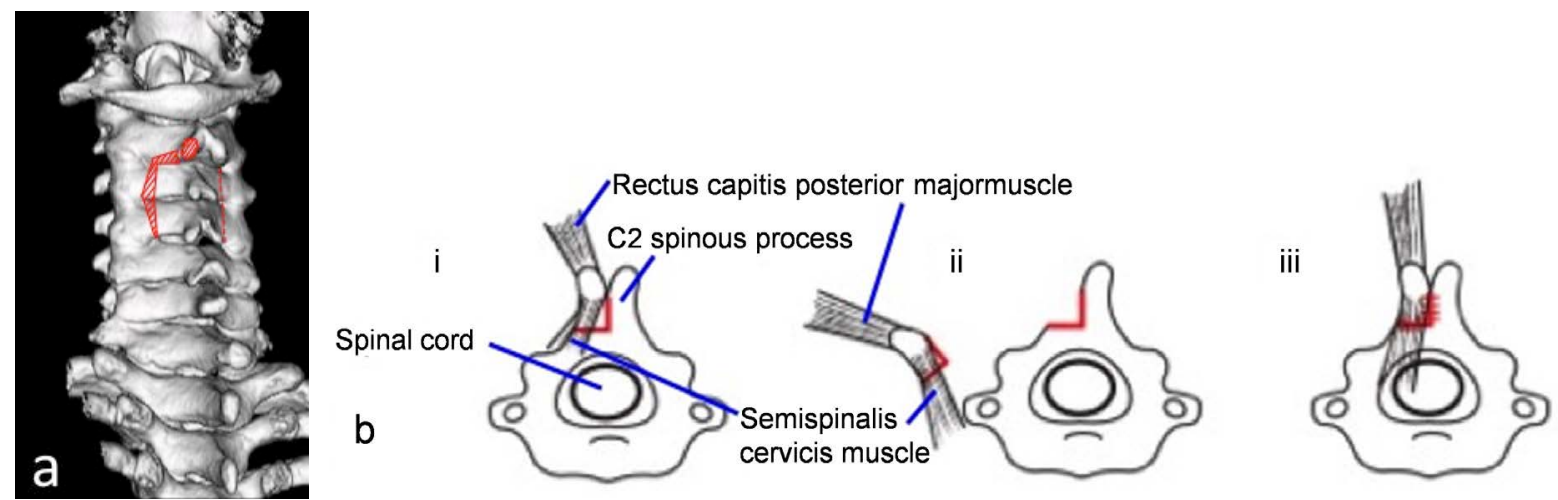

Figure 2. Preoperative 3D CT. (a) The solid line indicates the dissected area, the shaded part shows the area of bone resection, and the dotted line indicates the hinge section; (b) A scheme showing the deep layer extensors at the cervical spine. 1) The left side of the spinous process was additionally half-incised with the $\mathrm{C} 2$ spinous process-attached muscles still attached; 2) It was possible to observe under direct vision the outside part of the tumor via the intervertebral foramen at the $\mathrm{C} 3$ and $\mathrm{C} 4$ levels by introversion of the $\mathrm{C} 2$ spinous process to the left lateral side; 3 ) The $\mathrm{C} 2$ spinous process was restored and attached to the right side of the spinous process for reconstruction. 
that time, intraoperative pathology consultation led to the diagnosis of meningioma.

Then, the whole intradural section of the tumor was resected with the dura mater, which was considered the site of primary occurrence, with debulking advanced using a Cavitron Ultrasonic Surgical Aspirator. The defective area of the dura mater was sutured with artificial dura mater, and the inverted $\mathrm{C} 2$ spinous process was returned and sutured with a non-absorbable thread. A cervical collar was attached for one month after surgery. The case was classified as Simpson grade IV. Pathologically, meningioma was diagnosed. MIB- I staining-positive cells accounted for 3\% - 4\% of all cells in each field of vision (Figure 3).

The postoperative clinical course has been uneventful for 2 years after the operation, and her some symptoms have been alleviated. The JOA score was 17 points and Hirabayashi's recovery rate was $100 \%$ [4]. Computed tomography $(\mathrm{CT})$ at approximately 6 months after the operation revealed bony union at the $\mathrm{C} 2$ spinous process and preservation of the outside half of the $\mathrm{C} 3 / 4$ facet joint (Figure 4). MRI at 2 years after the operation demonstrated a residual tumor around the vertebral artery, but there was no apparent growth (Figure 5).

\section{Discussion}

To the best of our knowledge, only 8 cases with dumbbell meningioma developing at the cervical vertebral level have been reported to date [1] [5]-[11]. Schwannoma often develops into a dumbbell type. Meanwhile, meningioma develops from the arachnoid membrane and often adheres to, but rarely penetrates, the dura mater [12]. It grows along the inner side of the dura mater and is unlikely to develop into a dumbbell type. Therefore, the de-

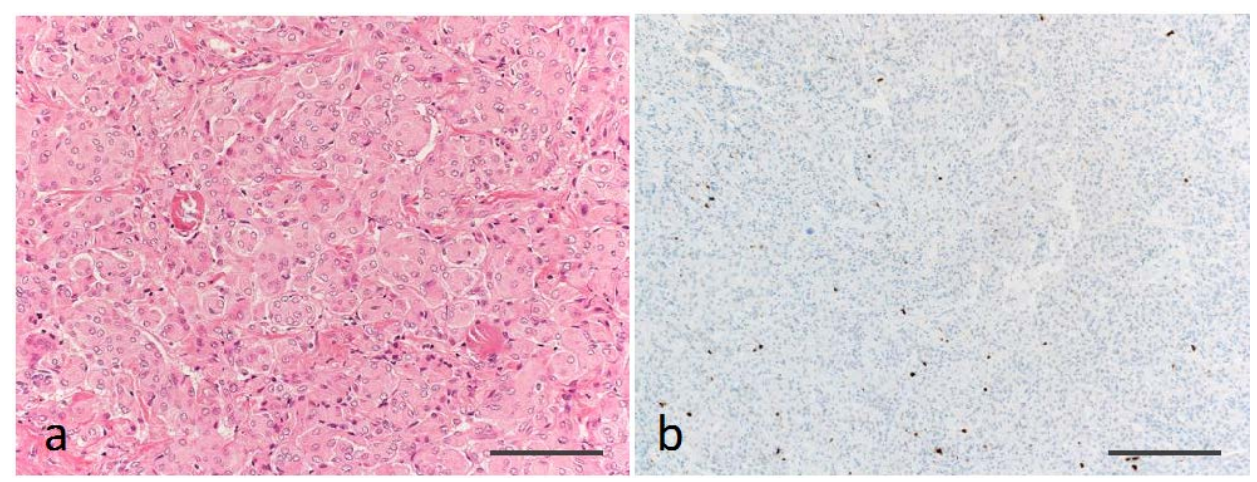

Figure 3. Pathohistological findings. (a) H.E. staining $(\times 200)$; (b) MIB-1 staining $(\times 100)$. Scale bars $=100 \mu \mathrm{m}(\mathrm{a})$, and 200 $\mu \mathrm{m}$ (b). Tumor cells consisted of an elliptical nucleus and eosinophilic cytoplasm, and psammoma bodies were also recognized. MIB-1 staining-positive cells accounted for 3\% - 4\% of all cells in each field of vision.

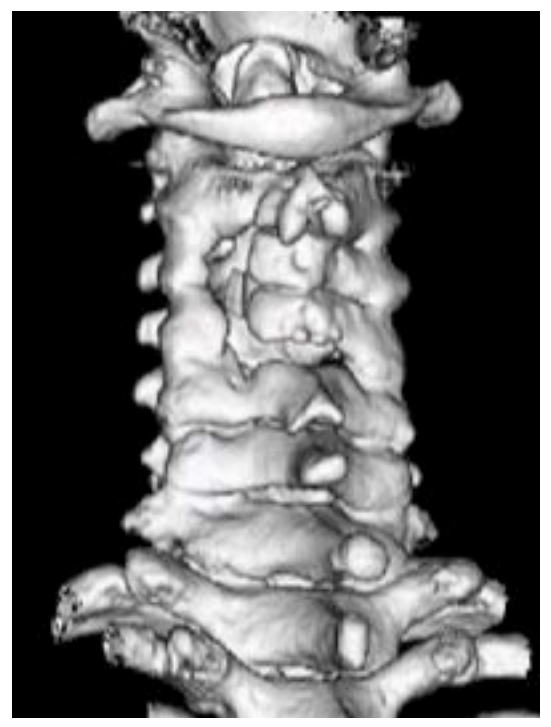

Figure 4. Posteropative 3D CT Synostosis was observed at the C2 spinous process. 
velopment of a dumbbell meningioma at the cervical vertebral level is markedly rare.

This is the sixth case report of dumbbell meningioma occurring at the cervical vertebral level and involving the vertebral artery [5]-[7] [9] [10] (Table 1). In all cases, the tumor was enucleated and resected only at Simpson grade IV [13]. The postoperative follow-up period showed a wide difference from 6 months to 5 years, but no case showed aggravation, such as recurrence. In our case, a residural tumor was observed around the vertebral artery. However, the JOA score was 17 points and Hirabayashi's recovery rate was $100 \%$. In addition, Yoshihara et al. mentioned that it was acceptable to resect partially the extradural part of a benign tumor adjacent to the vertebral artery to avoid injury to the artery [14]. Mirimanoff et al. [15] reported that the 10-year tumor recurrence rate of spinal cord meningioma was $13 \%$. Since the present case, at 76 years of age, was the oldest case described to date, the tumor around the vertebral artery was resected only as much as possible, with the risk of vertebral artery injury taken into account. Considering the result of our case, it is acceptable to resect partially the extradural part of low growth rate meningioma adjacent to the vertebral artery to avoid much risk in elderly cases.

Long-term symptomatic improvement is expected following complete resection of the intradural section of a tumor, including the dural occurrence site, and decompression of the cervical spinal cord. In the posterior approach for cases with a Eden's type-2 upper cervical dumbbell spinal tumor, inversion of the group of $\mathrm{C} 2$ spinous process-attached muscles with the spinous process still attached provides an excellent view of the $\mathrm{C} 2 / 3$ facet joint, including the caudal side, and enables maneuvers around the vertebral artery. In addition, reconstruction of $\mathrm{C} 2$ spinous process-attached muscles and bony union can be expected by returning the inverted $\mathrm{C} 2$ spinous process to its original position. Furthermore, postoperative vertebral instability and axial pain may be prevented.

\section{Conclusion}

This is a rare case of dumbbell meningioma occurring at the cervical spinal cord in an elderly patient. Even when total resection of meningioma is unfeasible and an extradural residual tumor is recognized, tumor growth is often slow, and one option is not to adhere to total resection in elderly cases when operative invasiveness is taken
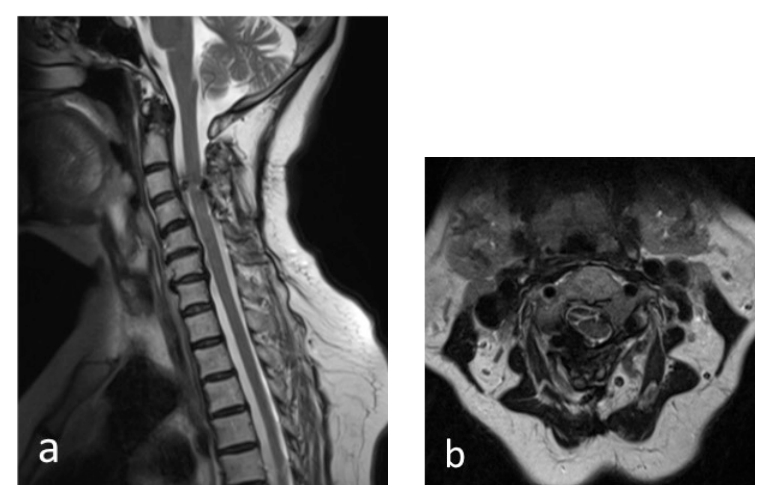

Figure 5. Postoperative MRI. (a) Sagittal and (b) axial T2-weighted images. A residual tumor was observed around the vertebral artery at the $\mathrm{C} 3 / 4$ level.

Table 1. Summary of cases with cervical dumbbell type meningioma in the literature.

\begin{tabular}{|c|c|c|c|c|c|c|}
\hline Reference & $\begin{array}{l}\text { Age } \\
\text { (years), sex }\end{array}$ & Level & $\begin{array}{l}\text { Simpson's } \\
\text { grade }\end{array}$ & $\begin{array}{l}\text { Postoperative residual tumor } \\
\text { around the vertebral artery }\end{array}$ & Recurrance $^{* *}$ & Follow-up period \\
\hline Ozaki et al. [5] & $49, \mathrm{~F}$ & $\mathrm{C} 2-4$ & IV & + & - & 2.5 years \\
\hline Hakuba et al. [6] & $60, \mathrm{M}$ & $\mathrm{C} 7-\mathrm{T} 1$ & IV & + & - & 5 years \\
\hline Yoshiura et al. [7] & $16, \mathrm{M}$ & $\mathrm{C} 2-4$ & IV & + & - & 8 months \\
\hline Chen et al. [9] & $16, \mathrm{~F}$ & $\mathrm{C} 1-2$ & IV & - & - & 10 months \\
\hline Clarke et al. [10] & $19, \mathrm{M}$ & $\mathrm{C} 7-\mathrm{T} 1$ & IV & + & - & 14 months \\
\hline Current case & $76, \mathrm{~F}$ & C3-4 & IV & + & - & 2 years \\
\hline
\end{tabular}

${ }^{*}+$ : A tumor remained around the vertebral artery; $-:$ A small piece of tumor remained over the posterior wall of the intervertebral foramen; ${ }^{* *}-:$ There was neither clinical nor radiologic evidence of tumor recurrence during the follow-up period. 
into account. Securing an intraoperative visual field and operative maneuvers are easier by inversion of the group of $\mathrm{C} 2$ spinous process-attached muscles with the spinous process still attached, and returning it to its original position after tumor extraction facilitates reconstruction.

\section{Consent}

The patients have given her informed consent for the case report to be published.

\section{References}

[1] Ozwa, H., Kokubun, S., Aizawa, T., Hoshikawa, T. and Kawahara, C. (2007) Spinal Dumbbell Tumors: An Analysis of a Series of 118 Cases. Journal of Neurosurgery: Spine, 7, 587-593. http://dx.doi.org/10.3171/SPI-07/12/587

[2] Simeone, F.A. (1975) Intraspinal Neoplasms. In: Rothman, R.H. and Simeone, F.A., Eds., The Spine, WB Saunders, Philadelphia, 35-42.

[3] Jinnai, T., Hoshimaru, M. and Koyama, T. (2005) Clinical Characteristics of Spinal Nerve Sheath Tumors :Analysis of 149 Cases. Neurosurgery, 56, 510-515. http://dx.doi.org/10.1227/01.NEU.0000153752.59565.BB

[4] Hirabayashi, K., Watanabe, K., Wakano, K., Suzuki, N., Satomi, K. and Ishii, Y. (1983) Expansive Opendoor Laminoplasty for Cervical Spinal Stenotic Myelopathy. Spine, 8, 693-699. http://dx.doi.org/10.1097/00007632-198310000-00003

[5] Ozaki, M., Nakamura, M., Tsuji, O., Iwatani, A., Toyama, Y., Chiba, K., et al. (2013) A Rare Case of Dumbbell Meningioma of Upper Cervical Spinal Cord. Journal of Orthopaedic Science, 18, 1042-1045. http://dx.doi.org/10.1007/s00776-012-0252-6

[6] Hakuba, A., Komiyama, M., Tsujimoto, T., Ahn, M.S., Nishimura, S., Ohta, T., et al. (1984) Transuncodiscal Approach to Dumbbell Tumors of the Cervical Spinal Canal. Journal of Neurosurgery, 61, 1100-1106. http://dx.doi.org/10.3171/jns.1984.61.6.1100

[7] Yoshiura, T., Shrier, D.A., Pilcher, W.H. and Rubio, A. (1998) Cervical Spinal Meningioma with Unusual MR Contrast Enhancement. American Journal of Neuroradiology, 19, 1040-1042.

[8] Buchfelder, M., Nomikos, P., Paulus, W. and Rupprecht, H. (2001) Spinalthoractic Dumbbell Meninjioma: A Case Report. Spine, 26, 1500-1504. http://dx.doi.org/10.1097/00007632-200107010-00026

[9] Chen, J.C., Tseng, S.H., Chen, Y., Tzeng, J.E. and Lin, S.M. (2005) Cervical Dumbbell Meningioma and Thoracic Dumbbell Schwannoma in a Patient with Neurofibromatosis. Clinical Neurology and Neurosurgery, 107, $253-257$. http://dx.doi.org/10.1016/j.clineuro.2004.06.012

[10] Clarke, M.J. and Krauss, W.E. (2006) Cervical Meningioma Masquerading as Schwannoma: Two Cases and a Review of the Literature. Journal of Neurosurgical Sciences, 50, 41-44.

[11] Watanabe, M., Sasaki, D., Yamamoto, Y., Iwashina, T., Sato, M. and Motida, J. (2009) Upper Cervical Spinal Cord Tumors: Review of 13 Cases. Journal of Orthopaedic Science, 14, 175-181. http://dx.doi.org/10.1007/s00776-008-1309-4

[12] Leestma, J.E. (1980) Brain Tumors. The American Journal of Pathology, 100, 239-316.

[13] Simpson, D. (1957) The Recurrence of Intracranial Meningiomas after Surgical treatment. Journal of Neurology, Neurosurgery \& Psychiatry, 20, 22-39. http://dx.doi.org/10.1136/jnnp.20.1.22

[14] Yoshihara, H., Matsuyama, Y., Goto, M., Tsuji, T., Sakai, Y., Nakamura, H., et al. (2003) Results of Surgical Treatment of Dumbbell-Type Neurinoma in the Cervical Region. Rinsho Seikei Geka, 38, 1209-1214. (In Japanease)

[15] Mirimanoff, R.O., Dosoretz, D.E., Linggood, R.M., Ojemann, R.G. and Martuza, R.L. (1985) Meningioma: Analysis of Recurrence and Progression Following Neurosurgical Resection. Journal of Neurosurgery, 62, 18-24. http://dx.doi.org/10.3171/jns.1985.62.1.0018 